\title{
Vortex Theory and Earth Dynamics
}

\author{
Valentino Straser $^{1}$ and Alessandro Ferrari ${ }^{2}$ \\ 1. Independent Researcher, Strada dei Laghi 8, Terenzo 43040, Italy \\ 2. Independent Researcher, Viale Podgora 17, Sant'Ilario D’Enza 42029, Italy
}

\begin{abstract}
Morphological evidence in active tectonic areas consisting of subcircular shapes suggests that these geometries may originate from alternative mechanisms to those described by translational dynamics of complex faults. The mechanics behind endogenic forces, in particular convection currents, hasn't been completely explained. Differing in density from upward flows developing in atmosphere and in water, magma upwelling from the mantle can trigger endogenic vortexes in particular conditions and due to Coriolis Force. At their onset and ascent phase, vortexes apply lateral forces as result of rotation, open their way toward the surface and over time stabilize the channel. Opposite to a rising linear flow which compacts overlying materials impeding their surge, vortex flows unload the materials externally and compact them on the lateral surface of the channel, thus making it more regular and stable. Torsional movements on the surface associated to vulcanites, lateral ramps and subcircular elevations, can be observed. Other phenomena that may be consequence of vortex dynamics are the volcanic cones showing pseudo-rotations in the morphologies surrounding the crater. In this study we suggest a modeling for a vortex theory which may explain the Earth dynamics in terms of spiraling movement and magma upwelling stabilizing over time.
\end{abstract}

Key words: Tectonic vortexes, volcanism, seismicity, Coriolis force, Global tectonics.

\section{Introduction}

In about a century, researches have laid the foundations for the understanding of the Earth dynamics and the geological manifestations which persistently alter the earth crust, also known as Global Tectonics. From the Continental Drift to the Plate Tectonics, as well as the Expanding Earth and the Geotectonic modeling by Beloussov, the underlying question is about the driving force generating the crust dynamics. In the present study, a modeling is proposed about the Vortex Tectonics, which may be applied to interpret complex phenomena, such as intraplate seismicity and volcanism, and circular structures both on the Oceanic floors and the Earth crust.

\subsection{Morphologies and Elevations Having Elliptical, Spiraling and Rounded Shape}

The distribution of tectonic vortexes as referred by Kober (1921) has been hypothesized both in

Corresponding author: Valentino Straser, Dr., professor, research field: earthquake prediction. E-mail: valentino.straser@alice.it. continental environment and in sea and ocean floors. Associated with seismic activity and the presence of magmatic rocks, these particular morphologies are generally evident in areas with negative magnetic anomalies [1] and illustrate the cause and effect relation of the internal dynamics of the Earth linked to convective processes [2].

The relationship between the convection currents in the mantle/lithosphere system and the earth dynamics has been part of a long debate within tectonophysics and the relationships with crust dynamics. For over a century, this topic has been discussed in the scientific community within various branches of geoscience as shown in the studies by Kreighauger (1902), Ampferer (1906), Schwinner (1919), Holmes (1928), Griggs (1932), Pekèris (1935), Kraus (1951), Hess (1962). Although never directly observed, the convection currents in the mantle produce their effects on the earth's crust in various ways, such as heat flow in the oceans and on the continents, and magnetic anomalies. The latter are the result of the effects caused by ferromagnetic materials dragged upward by 
convective movements, as shown by the laboratory simulations $[3,4]$.

Compared with the conceptual and streamline modeling issued by the first authors [5] from last century to work on them, the studies by Ref. [6], as well as the one by Ref. [3] have highlighted a complex three-dimensional modeling on the dynamics of the convective processes in the mantle, although it is still unclear to what extent this mechanism reflects the actual reality.

The different viscosity and temperature in the inner shells of the Earth induce the convective movements, which may occur both on a large scale with laminar flows and plume, and on a small scale with turbulent flows concentrated in limited areas of the Globe. The upward spiraling trajectories generated by complex motions in the mantle/lithosphere system have also been hypothesized by Ref. [7-12].

\subsection{Candidate Structures as Tectonic Vortexes}

In this essentially bibliographic study, with the exception of the survey area located in Northern Italy, zones have been investigated exhibiting evidence of rotation, tectonic spiral and seamount vortex. All main candidate structures as Tectonic Vortex which have been described by several authors on a global scale, are found in localized areas or cover a wider region, both in continental environment and in sea and ocean floors (Fig. 1).

We believe that vortex upwelling limited to particular areas may have created in the past, and may still be causing, superficial torsions and characteristic tectonic structures with curved and rounded morphologies in localized points of the earth's crust, which can be associated locally with typical distributions of the hypocenters of earthquakes.

The tectonic vortex and spiraling structures which can be observed on the earth's surface associated with specific convective dynamics induced by the Coriolis Force, are referred to as "Vortex Theory" in the present study.

First considering the Mediterranean basin, the geological structures which may be associated with vortexes are: Sestri Spiral, Aegean Spiral [13] South

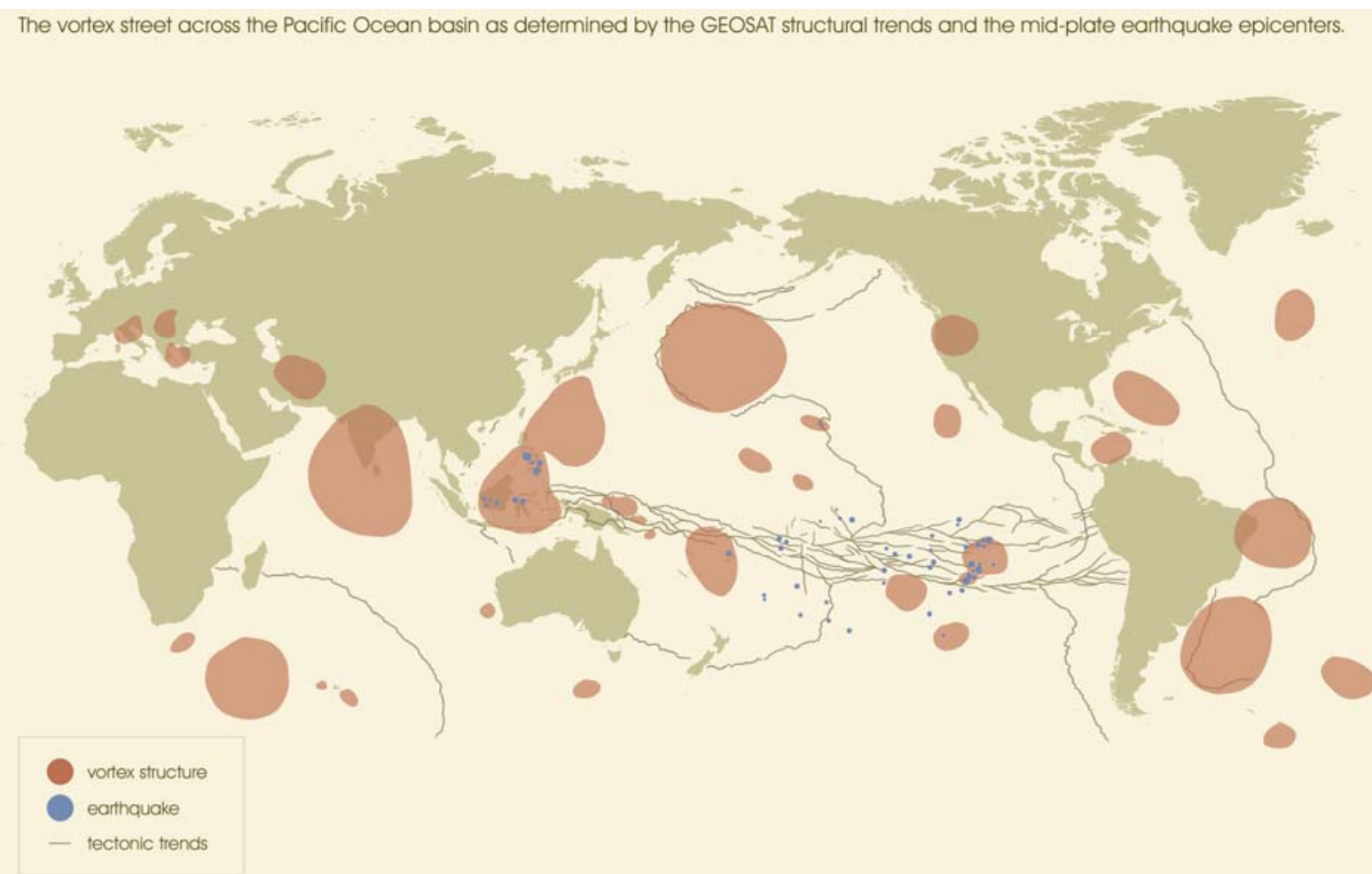

Fig. 1 Distribution of the tectonic vortexes on the Earth. The symbol on the figure is not scaled. 


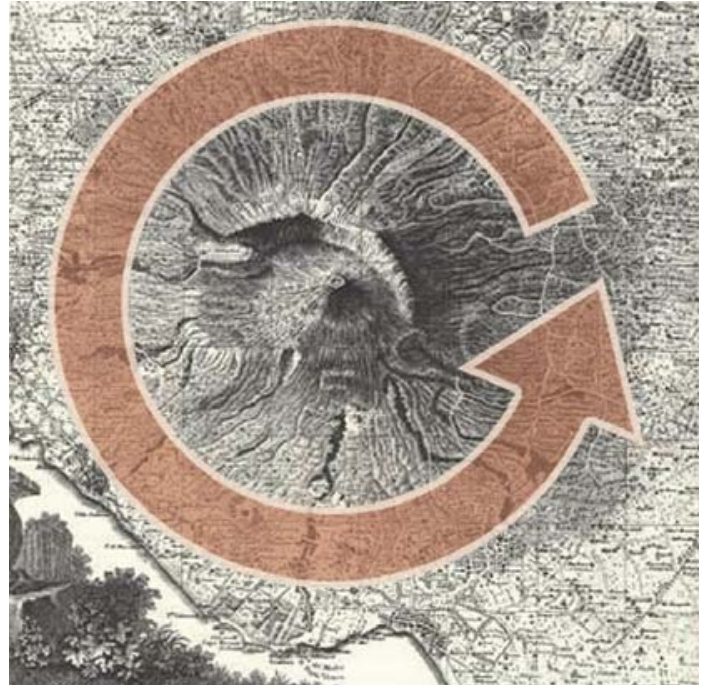

Fig. 2 Hypothesis about the trigger mechanism of an endogenic vortex and the morphology of Mount Vesuvius, Southern Italy, in an 18th century print showing a pseudo torsion.

Adriatic Basin, Seamount, west of Portugal [14].

In the Pacific Ocean, there are: Banda Sea Tectonic Vortex [1]. North Pacific Vortex, located in the region of Hess Rise/Emperor Fracture Zone/Emperor Seamount [15].

In the continental areas: Kersihir Spiral, Spiral of the Lut desert, Tibesti Spiral, and Arabia Spiral [16]; Pannonian Basin, Lake Victoria, Deccan Traps and Columbia River flood basalts. The latter are oval-like, subcircular and circular structures of about $1,000 \mathrm{~km}$ diameter [17].

In Central and Western Asia, the candidate structures as tectonic vortexes were described by Ref. $[18,19]$, and other authors.

Sub vortexes have been suggested in North Pacific Vortex, San Clemente fault zone [20], San Francisco Bay [14].

Alignment of the Australian Antarctic Discordance to other tectonic vortexes along the Western Pacific Rim. A mantle vortex north of Australia, and the Lake Baikal Continental Rift vortex in the northern hemisphere (upwelling mantle vortex) north of Australia with the Easter Island \& Juan Fernandez twin rotating micro-plates [21].

Like tectonic vortexes, signs of pseudo-rotations may be found in the morphologies of volcanoes with central cones and steep slopes in various zones of the Earth. Mount Vesuvius, Southern Italy, is an example in the Mediterranean basin (Fig. 2).

\section{From Local to Global}

Data provided by GPS [22] have allowed the temporal estimation of the monitoring stations in the Meditarranean basin. Kinematics analysis has shown evidence of the virgation of the Po Valley and the Aegean arc and both can be attributed to the middle and late Miocene.

(1) Detections performed by GPS have shown that in the Po Valley the movement speed is in the scale of 1-2 $\mathrm{mm} / \mathrm{yr}$ while in the Aegean Arc it is $20-30 \mathrm{~mm} / \mathrm{yr}$ [23]. Anderson and Jackson [24] have used the slip vectors of focal mechanisms around an Euler pole located in the Po Valley. The results derived from GPS data [25] were also confirmed by Calais et al. [26]. Data reading relative to the kinematics of the Valley connected to the dynamics in the Adriatic microplate [27] have shown a progressive rotation speed (Fig. 3) proceeding eastward and ranging from $1 \mathrm{~mm} / \mathrm{yr}\left(9^{\circ} \mathrm{E}\right)$ to $3 \mathrm{~mm} / \mathrm{yr}$ $\left(15^{\circ} \mathrm{E}\right)$.

It is important to note that the gradual variation in the direction of the structures is contemporary to their genesis, where the main detachments seem to be placed at the Messinian, and not due to any following rotation phenomenon linked to transcurrent activity [24].

The main component in the crust dynamics of the Po Valley consists of a curved upward movement, as reported by Gobetti and Perotti [28], relative to the increase of the crystalline basement, which is confirmed by geophysical, seismic and magnetic analysis. The higher zones with arc shape correspond to areas affected by intense magmatism. In particular, in the area of Pavia the crystalline basement presents a marked elevation where extended Tertiary volcanic bodies were identified and magnetic anomalies corresponding to the extension of the vulcanites. The absence of regional transcurrence and the presence of 


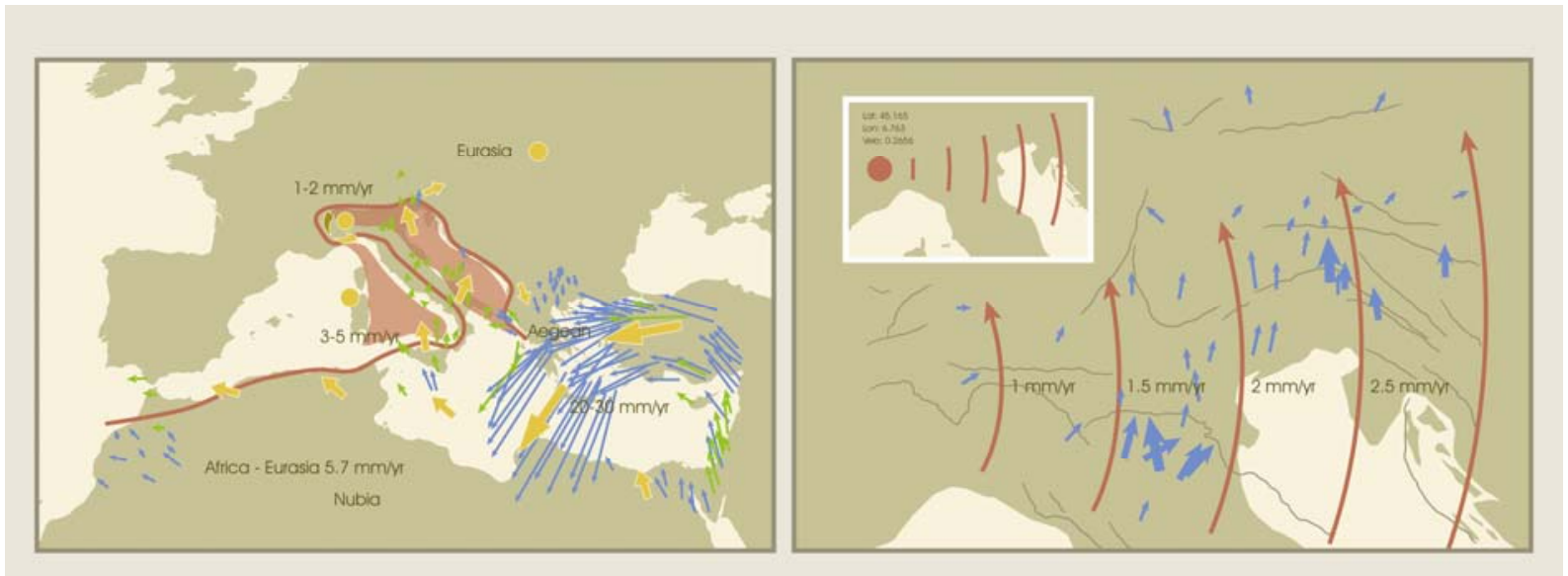

Fig. 3 Survey area with torsion in Po Valley, Northern Italy, and distribution of tectonic stress in the Aegean region. Taken and adapted from Serpelloni et al. (2007).

lateral ramps are capable to justify a marked change in direction caused by crustal rotation.

In the same area where crustal rotation is assumed, three main structural arches have been recognized: the arc of Monferrato, the arc of Emilia Romagna (very pronounced near Pavia) and the arc of Ferrara composed of different segments convex toward the plains [29].

The kinematics and the tectonics of the Aegean arc has been described by several authors [23, 30-32].

Mantovani et al. [33] have reconstructed the kinematics and deformation pattern in the Central and Eastern Mediterranean area using the finite element technique and plane stress approximation in elastic domain.

The modeling parameters have provided some interesting information about the sensitivity of displacement and deformation fields. Results closer to observation were obtained with a NE (5-8 mm/a) movement of Africa and a W (30 mm/a) movement of Anatolia. Further tests carried out with other types of kinematics produced some aspects of the deformation field hardly compatible with the deformative pattern observed in the Central Mediterranean.

According to the interpretation suggested by Taymaz et al. [30], palaeomagnetic data in this eastern region are more ambiguous but consistent with very small or no rotations in the northern part and possibly anticlockwise rotations, relative to Europe, in the south. The strike-slip faulting that enters the central Aegean from the east appears to end abruptly in the SW against the NW-trending normal faults of Greece.

The widespread Middle Miocene granitic magmatism in the Cyclades suggests that flow in the lower crust may have had a dominant role in maintaining the smooth Moho [34].

The timeline for the cases considered in this study is the Messinian and, as far as the Mediterranean basin is concerned, also the Salinity crisis of the late Miocene has been taken into account. The Mediterranean basin shows complex structural and geodynamic contexts which are difficult to connect to each other, as confirmed in accurate seismic profiles and the analysis of sedimentary deposits [35]. Besides candidate Tectonic Vortexes, in the Meditarranean basin salt domes are present, which derive from a vertical dynamics and may as well be found in basins different in terms of crust dynamic [36-38] and not synchronous as to the timeline considered [39]. The presence of a seemingly unrelated vortex tectonics, with the exception of regional scales, suggests that a mechanism may have operated also in the preceding eras, though nowadays it is hardly recognizable. This is the case of Northwestern Africa where curved structures are observed in Burkina Faso and Mali [40], consisting of curved elevations surrounding the sedimentary basin of 
Taoudenni and dike swarms [41] which may directly come from the mantle by injection through the crust. The alleged presence of magmatic dikes, detected with the magnetometer, were also identified in Gambia [42], Western Sahara, Mauritania and Liberia.

\section{The Modeling}

The magma farther from the edges of the plate applies strong upward pressure which struggles to find an outlet. If it finds an opening, probably narrower than the magma mass flowing up, a slow rotation due to the Coriolis force or other local forces will lead to the formation of a magma vortex. Approaching the channel of ascent, the magma generates a strong increase in the rotation speed due to the conservation of angular momentum, only partially reduced by the viscosity of the magma itself.

The phenomenon is similar to air vortices, e.g. tornadoes, or water vortices, e.g. whirlpools, but differs primarily in that there is (a) much higher density and viscosity, (b) much higher pressure, and (c) a difference in viscosity with the medium that opposes the upward movement similar to the whirlpools which are created with an opening on the bottom of a container, when emptying sinks and bathtubs.

The observation of such phenomena not only on the Earth but also on Jupiter, Saturn and the Sun, confirms the generalization of the phenomenon in conditions with extremely varied physical parameters, and supports the reliability of the hypothesis about their formation during magma upwelling.

The upward flow along the channel without the rotation of the magma would lead to a strong compression of the overlying material until it reached one of the following situations:

(1) the pressure of the magma leads to an interruption of the upwelling and balance is reached;

(2) a new fragile and/or favorable zone is approached and magma is allowed to lateral movement and possibly a new upwelling;

(3) the surface is reached.
This would lead to a oftentimes tortuous upward route according to local features. If this were the case, it would be reasonable to assume a network of wells, with irregular paths connected through chambers and other intermediate structures. (Fig. 4)

In addition, the strong upward compression could lead more frequently to collapses in the duct once the magmatic pressure were to fall significantly. This means that any further attempt to move upward may be diverted to alternative routes, given the strong dependence on the local features which would be altered during the same collapses.

Whereas, the presence of a vortex in the magma upwelling would lead to unload most of the overlying material to be found during the rising on the external part of the channel and to compact it along the walls of the channel itself. (Fig. 4)

In this way, the overhead pressure would not be increased by the magma upwelling, allowing an easier and extended upward movement. Besides, the gyroscopic effect would help stabilize the route by forming ducts along the most direct way.

If no load is accumulated above, while better compacting the material along the channel walls and facilitating the formation of more regular ducts, i.e. straighter and with circular section, stabler structures would be generated, which would also be less subject to collapse even with dramatic reduction of the

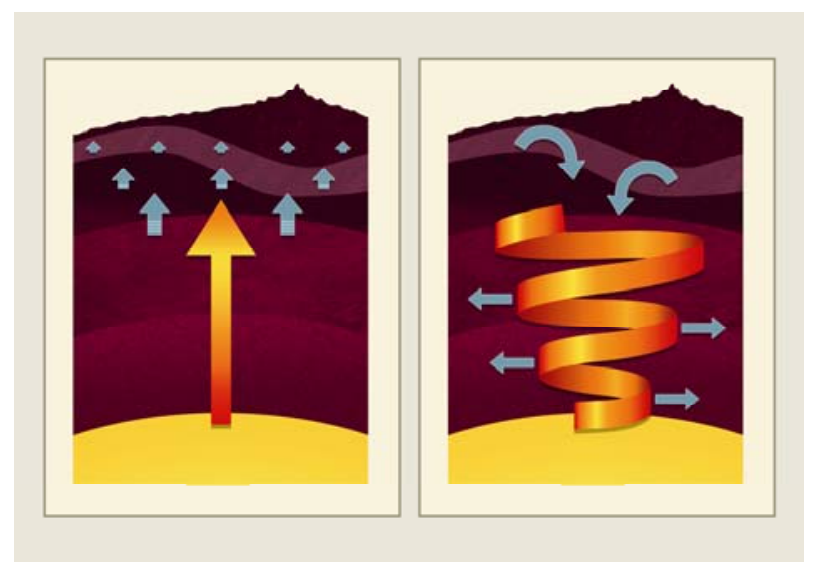

Fig. 4 Comparing laminar flow which compacts overlying materials, and spiraling upward vortex which unloads the stress laterally, subsidence at the center. 
magmatic pressure. (Fig. 4)

This greater stability would allow subsequent magma waves to flow through the same channel, thus stabilizing it further, as long as the wave occurrence were within reasonable time compatible with the viscosity of the zone. This type of channel re-using is not at all possible in air vortexes such as tornadoes, or water vortexes such as whirlpools, because of the very low viscosity of these means, but it is plausible in materials which are enormously more viscous like in the lithosphere and probably in the mantle as well-for upward waves frequent enough which depend on the internal dynamics of the Earth.

It seems reasonable then to hypothesize vortex upwelling in magmatic chambers if

(1) they are larger in relation with the upwelling channel section;

(2) they contain less viscous magma in relation to temperature, pressure and features of magma material;

(3) they allow a faster upward movement.

Thus, the upwelling channels from these chambers should be approximately cylindrical and vertical, quite stable and re-used over time. On the contrary, it is legitimate to hypothesize mainly non-spiraling upwelling in such basins

(1) that are smaller or in assorted shapes;

(2) that contain more viscous magma;

(3) that allow upward movement faster than the incandescent materials.

The upwelling routes covered from these chambers should then be more varied, less direct and changing over time.

Based on the abovementioned criteria, many volcanoes could be characterized by magma upwelling of the vortex type since the upward movement is quite fast and the relationship between the magmatic chamber and the upwelling channel section is reasonably high.

The fact that the eruption will occur in the same spot despite the accumulation of material which obstructs the exit, means that the upwelling channel is quite stable and direct, and that the eruptions do not undermine its stability, but rather consolidate it. All this is compatible with the mechanism of vortex upwelling as described above.

Observing many volcanoes from above, spiraling structures can be seen radiating from the center, which are more than compatible with vortex upwelling and the superficial lines of force that would derive from it.

\section{Conclusions}

The vortex modeling illustrated in the present study appears to be a good candidate to explain conformations and dynamics of many geological structures. In particular, structures presenting spiraling morphologies or lines of force with marked torsion find in this vortex modeling a physical mechanism able to explain how they could have generated.

The vortex modeling is a candidate as physical mechanism able to explain also the phenomena in which the magmatic upwelling channel, and any relative exit point, do not vary but remain particularly stable and localized with recurring events over time. Many volcanoes show both these characteristics and are therefore especially interesting in order to confirm or reject the modeling introduced here.

We believe that further study on the geological structures presented in this article, and more, according to the criteria set out in the model, could extend the knowledge of the upward movement of the mantle upwelling, thus confirming or rejecting the presence of vortex motions and help highlight any difference in dynamics at various scales of action.

\section{Acknowledgments}

The authors thank $\mathrm{AB}$ Global for supporting this research work and Dr Sara Ghirardi for linguistic revision.

\section{References}

[1] Leybourne, B. A., and Adams, M. B. 2001. "El Niño Tectonic Modulation in the Pacific Basin." Oceans 4: 
2400-6.

[2] Straser, V. 2014. "Geo Spots and Vortex Theory." Geophysical Research Abstracts 16 (May): EGU2014-7985.

[3] Glatzmaier, G. A., and Olson, P. 2005. "Probing the Geodynamo." Scientific American 292: 50-5.

[4] Bercovici, D. 2003. "The Generation of Plate Tectonics from Mantle Convection." Earth and Planetary Science Letters 205 (3): 107-21.

[5] Holmes, A. 1931. "Radioactivity and Earth Movements." Transactions of the Geological Society of Glasgow 18 (3): 559-606.

[6] Bercovici, D., Schubert, G., and Glatzmaier, G. A. 1989. "Three-278 Dimensional Spherical Models of Convection in the Earth's Mantle." Science 244: 950-5.

[7] Verhoeven, J., Wiesehofer, T., and Stellmach, S. 2015. "Anelastic Versus Fully Compressible Turbulent Convection.” The Astrophysical Journal 805 (62): 23.

[8] Brummell, N., Hurlburt, N., and Toomre, J. 1998. "Turbulent Compressible Convection with Rotation. II. Mean Ows and Differential Rotation." The Astrophysical Journal 493 (2): 955-69.

[9] Brun, A. S., Miesch, M. S., and Toomre, J. 2004 "Global-Scale Turbulent Convection and Magnetic Dynamo Action in the Solar Envelope." Astrophys. J. 614 (2): 1073-98.

[10] Wang, S., Zhang, S., and Yuen, D. A. 2007. "Visualization of Downwellings in 3-D Spherical Mantle Convection." Physics of the Earth and Planetary Interiors 163 (1-4): 299-304.

[11] Evonuk, M., and Samuel, H. 2012. "Simulating Rotating Fluid Bodies: When is Vorticity Generation via Density-Stratification Important?" Earth and Planetary Science Letters 317-318 (February): 1-7.

[12] Yanagisawa, T., and Yamagishi, Y. 2005. "Rayleigh-Bénard Convection in Spherical Shell with Prandtle Number at High Rayleigh Number." Journal of the Earth Simulator 4: 11-7.

[13] Leybourne, B., Smoot, C., Gregori, G. P., Paparo, G., and Ismail Bhat, I. 2008. "Tectonic Spiral Structures of the Tethyan Vortex Street: GRACE Geoid Interpretations and African Lightning Teleconnections." Presented at the 33rd IGC, Oslo NCGT Symposium, Oslo, Norway.

[14] Smoot, N. C., and Leybourne, B. A. 1997. "Vortex Structures on the World-Encircling Vortex Street: Case Study of the South Adriatic Basin.” Marine Technology Society Journal 31 (2): 21-3.

[15] Smoot, N. C. 1997. "Seafloor Fabric Produced by Surge Tectonics." In Proceedings of the 4th Them. Conf. Rem. Sens. Mar. Coast. Env., 518-27.

[16] Neev, D., and Hall, J. 1982. "A Global System of Spiraling Geosutures.” Journal of Geophysical Research 87 (B13):
10.

[17] Meyerhoff, A. A., Taner, I., Morris, A. E. L., Martin, B. D., Agocs, W. B., and Meyerhoff, H. A. 1992. "Surge Tectonics: A New Hypothesis of Earth Dynamics." In New Concepts in Global Tectonics, edited by Chatterjee, S., and Hotton, N. Vol. 3. Lubbock: Texas Tech University Press, 309-409.

[18] Shengzu, W. 1998. "Mantle Vortex Convection in Central Eastern Asia and the "Vortex/Network" Continental Dynamics Model." Seismology and Geology 20 (4): 379-90.

[19] Shengzu, W., Jianguo L., and Zongchun Z. 2000. "Experimental Study of Mantle Convection: Non Columnar Plume and Mantle Vortex." Seismology and Geology 22 (2): 155-66.

[20] Legg, M. R., Luyendyk, B. P., Mammerickx, J., deMoustier, C., and Tyce, R. C. 1989. "Sea Beam Survey of an Active Strike-Slip Fault: The San Clemente Fault in the California Continental Borderland." Jour. Geophys. Res. 94 (B2): 1727-44.

[21] Leybourne, B., Smoot, C., and Longhinos, B. 2014. "World Encircling Tectonic Vortex Street-Geostreams Revisited: The Southern Ring Current EM Plasma-Tectonic Coupling in the Western Pacific Rim." Geophysical Research Abstracts 16: EGU2014-16736.

[22] Mantovani, E., Babbucci, D., Viti, M., Albarello, D., Mugnaioli, E., Cenni, N., and Casula, G. 2006. "Post-Late Miocene Kinematics of the Adria Microplate: Inferences from Geological, Geophysical and Geodetic Data." In The Adria Microplate: GPS Geodesy, Tectonics, and Hazards, edited by PINTER, N. Netherlands: Springer, 51-69.

[23] Serpelloni, E., Vannucci, G., Pondrelli, S., Argnani, A., Casula, G., Anzidei, M., Baldi, P., and Gasperini, P. 2008. "Kinematics of the Western Africa-Eurasia Plate Boundary from Focal Mechanisms and GPS Data." Geophysical Journal International 169 (3): 1180-200.

[24] Anderson, H., and Jackson, J. 1987. "Active Tectonics of the Adriatic Region." Royal Astronomical Society Geophysical Journal 91 (3): 937-83.

[25] Weber, J., Vrabec, M., Pavlovčič-Prešeren, P., Dixon, T., Jiang, Y., and Stopar, B. 2010. "GPS-Derived Motion of the Adriatic Microplate from Istria Peninsula and Po Plain Sites, and Geodynamic Implications." Tectonophysics 483 (3-4): 214-22.

[26] Calais, E., Nocquet, J. M., Jouanne, F., and Tardy, M. 2002. "Current Strain Regime in the Western Alps from Continuous Global Positioning System Measurements, 1996-2001." Geology 30 (7): 651-4.

[27] Babbucci, D., Tamburelli, C., Viti, M., D’Onza, F., Mugnaioli, E., Mantovani, E., Albarello, D., and Cenni, N. 2002. "Cinematica Della Placca Adriatica Rispetto All' Eurasia e All' Africa: Vincoli Sismologici e Geodetici." GNGTS-Atti del $22^{\circ}$ Convegno Nazionale/02.02. 
[28] Gobetti, A., and Perotti, C. R. 1990. "Genesi e Caratteristiche Dell'Arco Strutturale di Pavia." Atti Ticinesi Scienze Terra, 143-56.

[29] Pieri and Groppi, 1981. "Subsurface Geological Structure of the Po Plain." Progetto Finalizzato Geodinamica/Consiglio Nazionale Delle Ricerche 414: 23.

[30] Taymaz, T., Jackson, J., and McKenzie, D. 1991. "Active Tectonics of the North and Central Aegean Sea." Geophysical Journal International 106 (2): 433-90.

[31] McKenzie, D. 1978. "Active Tectonics of the Alpine-Himalayan Belt: The Aegean Sea and Surrounding Regions." Geophysical Journal International 55 (1): 217-54.

[32] Avigad, D., Baer, G., and Heimann, A. 1998. "Block Rotations and Continental Extension in the Central Aegean Sea: Palaeomagnetic and Structural Evidence from Tinos and Mykonos (Cyclades, Greece). " Earth and Planetary Science Letters 157 (1-2): 23-40.

[33] Mantovani, E., Cenni, N., Albarello, D., Viti, M., Babbucci, D., Tamburelli, C., and D’Onza, F. 2001. "Numerical Simulation of the Observed Strain Field in the Central-Eastern Mediterranean Region." J. Geodynamics 31 (5): 519-56.

[34] Reilinger, R., McClusky, S., Paradissis, D., Ergintav, S., and Vernant, P. 2010. "Geodetic Constraints on the Tectonic Evolution of the Aegean Region and Strain Accumulation along the Hellenic Subduction Zone." Tectonophysics 488 (1-4): 22-30.

[35] Lofi, J., Deverchere, J., Gaullier., V., Gillet, H., Gorini, C., Guennoc, P., Loncke, L., Maillard, A., Sage, F., Thinon, I., Capron, A., and Obone Zue Obame, E. 2007. "The Messinian Salinity Crisis in the Offshore Domain: An Overview of Our Knowledge through Seismic Profile Interpretation and Multi-site Approach.” In Proceedings of
CIESM Workshop Monographs, 83-90.

[36] Roveri, M., Ranero, C. R., Sartori, R., Torelli, L., and Zitellini, N. 2004. "Seismic Images and Magnetic Signature of the Late Jurassic to Early Cretaceous Africa-Eurasia Plate Boundary off SW Iberia." Geophys. J. Int. 158 (2): 554-68.

[37] Ashwal, L. D., and Burke, K. 1989. "African Lithospheric Structures, Volcanism and Topography." Earth and Planetary Letters 96 (1-2): 8-14.

[38] Brown, C., and Girdler, R. W. 1980. "Interpretation of African Gravity and Its Implication for the Breakup of the Continents." J. Geophys. Res. 85 (B11): 6443-55.

[39] Loncke, L., Gaullier, V., Mascle, J., Vendeville, B., and Camera, L. 2006. "The Nile Deep-Sea Fan: An Example of Interacting Sedimentation, Salt Tectonics, and Inherited Subsalt Paleotopographic Features." Marine and Petroleum Geology 23 (3): 297-315.

[40] El Abbass, T., Person, A., Gerard, Y., Sauvage, M., Sauvage, J. F., and Bertil, D. 1993. "Geophysical and Geological Arguments for Recent Volcanic Events in Faguibine Lake Zone (Mail)." Paris, Accadémie des Sciences Comptes Rendus 316 (2): 1303-10.

[41] Verati, C., Bertrand, H., and Féraud, G. 2005. "The Farthest Record of the Central Atlantic Magmatic Province into West Africa Craton: Precise 40Ar/39Ar Dating and Geochemistry of Taoudenni Basin Intrusives (Northern Mali)." Earth and Planetary Sciences Letters 235 (1-2): 391-407.

[42] Youbi, N., Kouyate, D., Söderlund, U., Ernst, R. E., Soulaimani, A., Hafid, A., Ikenne, M., El Bahat, A., Bertrand, H., Chaham, K. R., Ben Abbou, M., Mortaji, A., El Ghorfi, M., Zouhair, M., and M'hamed El Janati. 2013. "The 1750 Ma Magmatic Event of the West African Craton (Anti-Atlas, Morocco)." Precambrian Research 236 (October): 106-23. 